\title{
ЧЕЛОВЕЧЕСКИЙ КАПИТАЛ, КАК ЭЛЕМЕНТ РАЗВИТИЯ СТРАТЕГИЧЕСКОГО ПЛАНИРОВАНИЯ В РФ (НАЦИОНАЛЬНЫЙ ПРОЕКТ «ЗДРАВООХРАНЕНИЕ»)
}

(c) 2021 Петров А. М.

доктор экономических наук, профессор Департамента бизнес-аналитики

Финансовый университет при Правительстве Российской Федерации, Россия, Москва

E-mail:palmi@inbox.ru

Государственное стратегическое планирование, являясь составной частью государственного стратегического управления, представляет собой ключевой инструмент модернизации функционирующей системы государственного управления. Человеческий капитал, как этап развития стратегического планирования в РФ, в статье рассмотрен на основе национального проекта - «Здравоохранение».

Ключевые слова: человеческий капитал, здравоохранение, образование, демография, государственное стратегическое планирование.

Важным этапом развития стратегического планирования в РФ стало подписание 07 мая 2018 г. Указа Президента РФ N 204 «О национальных целях и стратегических задачах развития Российской Федерации на период до 2024 года» [1], по результатам которого были разработаны национальные проекты (далее - НП) по 3 направлениям, представленным на рисунке 1 , которые, как отметил В.В.Путин должны «поставить экономику на новые рельсы, сделать её высокотехнологичной, повысить производительность труда и на этой базе поднять уровень жизни наших граждан, обеспечить безопасность нашего государства на длительную историческую перспективу» [2].
Каждое из направлений включает в себя несколько национальных проектов, раскрывающих общую задачу развития той или иной сферы. Реализация каждого национального проекта конкретизируется входящими в его состав федеральными проектами (далее - ФП).

Направление «Человеческий капитал» объединяет 4 национальных проекта, главной целью которых является развитие человеческого капитала как ключевого элемента увеличения конкурентных преимуществ государства. Человеческий капитал объединяет знания, навыки, способности, опыт, показатели здоровья населения, накапливаемые на протяжении всей жизни и капитализируемые при создании добавленной

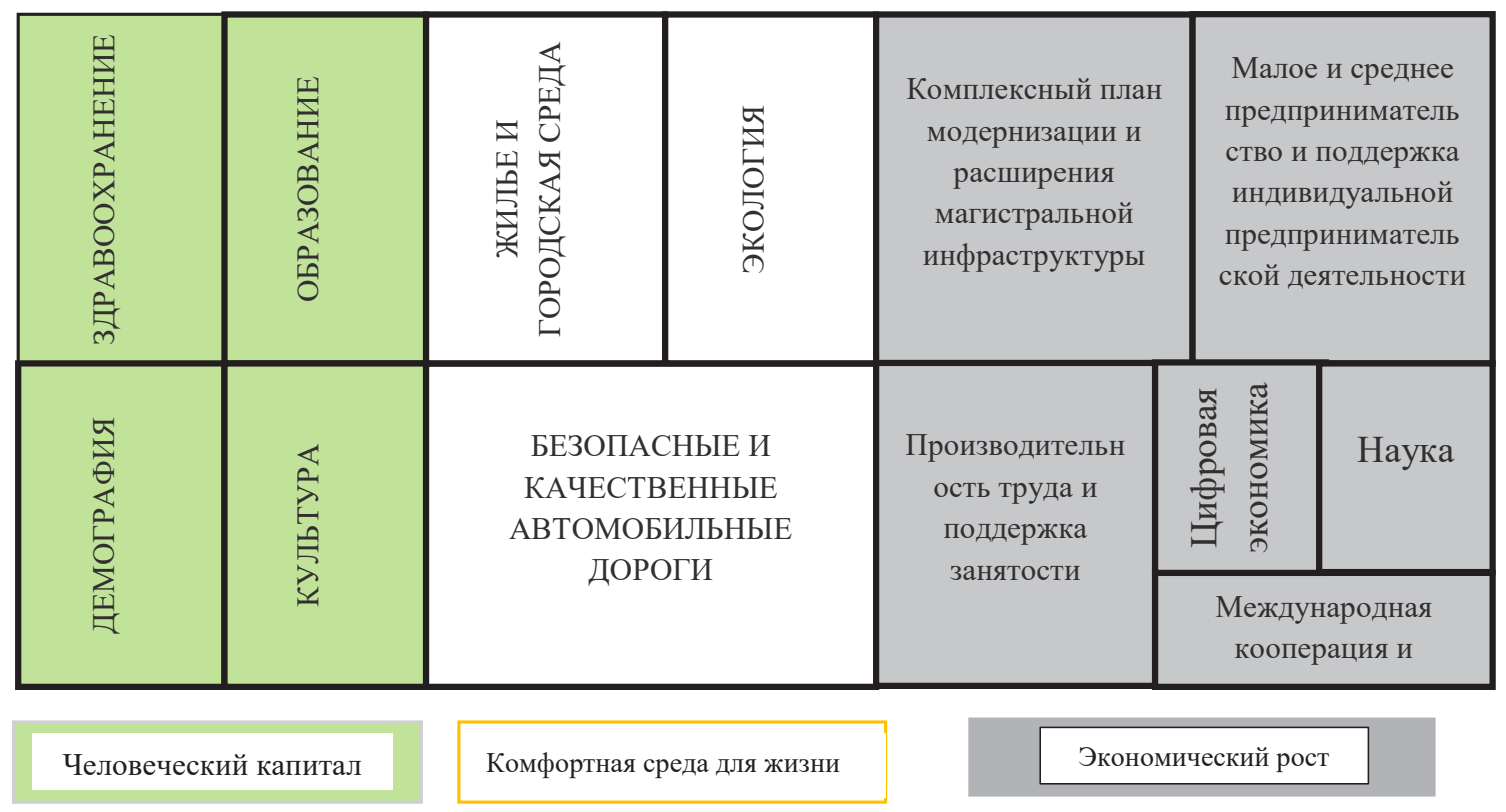

Рисунок 1. Национальные проекты России 2019-2024 
стоимости.

Федеральные проекты, входящие в национальный проект «Здравоохранение», представленные на рисунке 2 , направлены на улучшение, сохранение, восстановление, поддержание состояния здоровья населения страны.

В соответствии с определением здоровья, данным в Уставе Всемирной организации здравоохранения (далее - ВО3), под ним понимается состояние «полного физического, душевного и социального благополучия, а не только отсутствие болезней и физических дефектов» [3].

Вместе с тем для достижения данной цели, необходимо также создание условий, которые позволят контролировать основные детерминанты здоровья населения, то есть факторы, оказывающие положительное или отрицательное влияние на здоровье человека чему в значительной степени, будет способствовать реализация федерального проекта «Создание единого цифрового контура в здравоохранении на основе единой государственной информационной системы здравоохранения (ЕГИСЗ)».

Под социальными детерминантами здоровья ВО3 определяет «условия, в которых люди рождаются, растут, живут, работают и стареют, включая системы здравоохранения» [5], они могут оказывать как прямое, так и косвенное влияние на здоровье населения. Так, например, бедность оказывает косвенное воздействие на состояние здоровья населения в силу невозможности приобретения качественных продуктов питания, изменений условий проживания, получения доступа к медицинской помощи.

По результатам опроса, проведенного Всероссийским центром изучения общественного мнения (далее - ВЦИОМ) в 2019 г., представленном на рисунке 3, среди основных причин, оказывающих негативное влияние на состояние здоровья россиян были названы работа и стресс (33\% в 2019 г. против 35\% в 2017 г.), нехватка денежных средств на лечение и профилактику болезней (28\% в 2019 г. против 35\% в 2017 г.), возраст и отсутствие времени на отдых (25\% в 2019 г. против 28\% в 2017 г.).

По результатам исследования отношения россиян к российскому здравоохранению в 2019 г., представленному на рисунке 4, среди основных проблем российского здравоохранения, которые должны решаться в первую очередь,

- Борьба с онкологическими заболеваниями

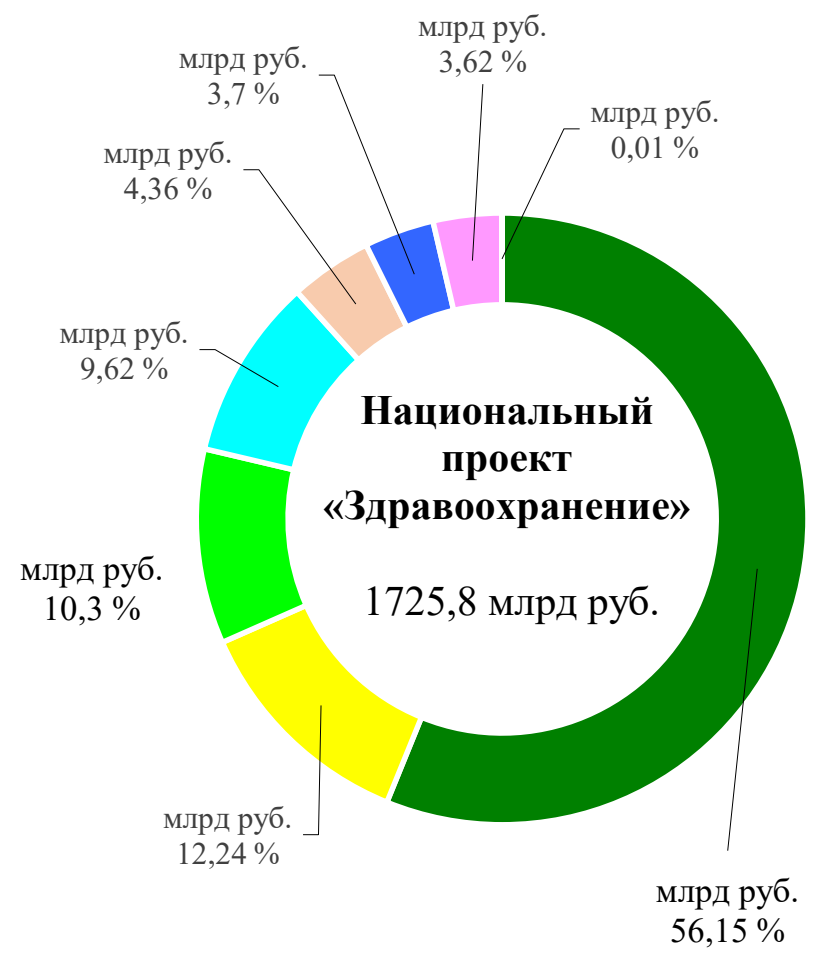

- Развитие детского здравоохранения, включая создание современной инфраструктуры оказания медицинской помощи детям

- Создание единого цифрового контура в здравоохранении на основе единой государственной информационной системы

- Обеспечение медицинских организаций системы здравоохранения квалифицированными кадрами

Борьба с сердечно-сосудистыми заболеваниями

- Развитие сети национальных медицинских исследовательских центров и внедрение инновационных медицинских технологий

- Развитие системы оказания первичной медикосанитарной помощи

- Развитие экспорта медицинских услуг здравоохранения (ЕГИСЗ)

Рисунок 2. Общий объем финансирования федеральных проектов, входящих в состав национального проекта «Здравоохранение» Источник: составлено материалам [4]. 


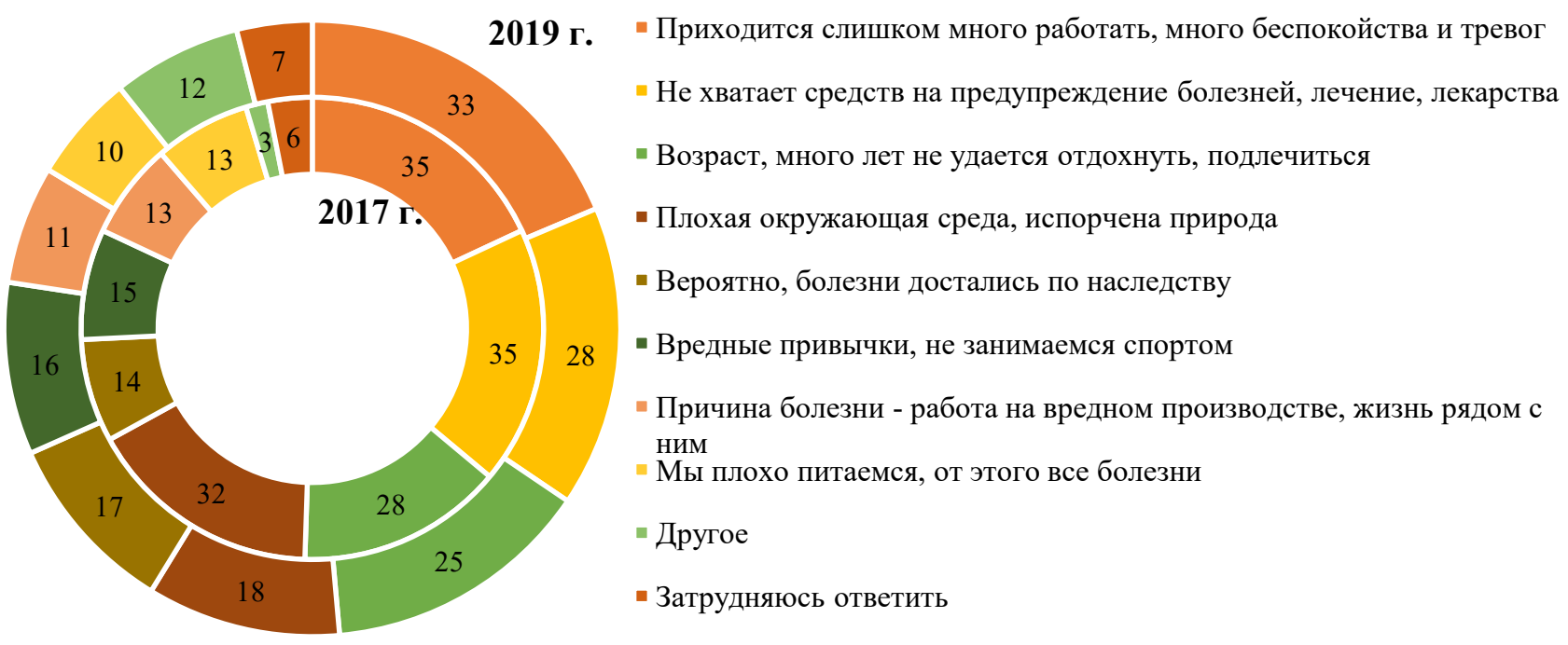

Рисунок 3. Оценка основных причин болезней россиян по данным опроса ВЦИОМ в 2019 г. при возможности выбора не более 3 ответов, в\% от всех опрошенных Источник: составлено по материалам [6].

\section{$\begin{array}{llllllllll}0 & 5 & 10 & 15 & 20 & 25 & 30 & 35 & 40 & 45\end{array}$}

Нехватка врачей

Недостаточная оснащенность.

$$
\text { . }
$$

Недоступность медицинской помощи.

Недостаток финансирования.

$$
\text { .... }
$$

Недостаточное обеспечение.

Взяточничество

..

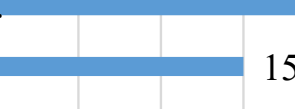

Недостаточный контроль за качеством.

Невежливое отношение со стороны.

... 12

Несовершенство законодательства

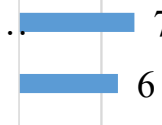

Неэффективная работа страховых... 4

Другое

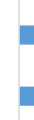

Затрудняюсь ответить

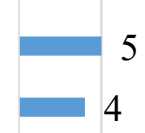

\section{5}

4

Рисунок 4. Оценка основных проблем российской системы здравоохранения по данным опроса ВЦИОМ в 2019 г. при возможности выбора не более 3 ответов, в \% от всех опрошенных Источник: составлено по материалам [7].

были названы: нехватка врачей (39\% опрошенных), недостаток современного оборудования (33\% опрошенных), неудовлетворительный уровень профессиональной подготовки (30\% опрошенных).

Таким образом, реализация запланированных в рамках национального проекта «Здравоох- ранение» федеральных проектов будет способствовать решению проблем российской системы здравоохранения, способствуя улучшению доступности и качества медико-санитарной помощи на основе использования новых технологий и модернизации медицинских учреждений. 


\section{Библиографический список}

1. Указ Президента РФ от 07.05.2018 № 204 (ред. от 19.07.2018) «О национальных целях и стратегических задачах развития Российской Федерации на период до 2024 года» // СПС КонсультантПлюс.

2. Прямая линия с Владимиром Путиным // Президент России: официальный сайт. - 2019. -20 июня.- Текст: электронный. - URL: http://kremlin.ru/events/president/news/60795.

3. Основные документы // Всемирная организация здравоохранения: [сайт].- Текст: электронный.- URL: http://apps.who.int/gb/bd/PDF/bd48/basic-documents-48th-edition-ru.pdf?ua=1\#page=9.

4. Национальный проект «Здравоохранение» // Будущее России. Национальные проекты: [сайт].- Текст: электронный. - URL: https://futurerussia.gov.ru/zdravoohranenie.

5. Социальные детерминанты здоровья // Всемирная организация здравоохранения: [сайт].- Текст: электронный. - URL: https://www.who.int/topics/social_determinants/ru/.

6. Тяжкий труд, бедность и старость: три причины болезней в России // Всероссийский центр изучения общественного мнения: [сайт].- 2019.- 16 мая.- Текст: электронный.- URL: https://wciom.ru/index. php?id=236\&uid $=9687$.

7. Качество медицинских услуг: запрос на жесткий контроль // Всероссийский центр изучения общественного мнения: [сайт].- 2019.- 11 декабря.- Текст: электронный.- URL: https://wciom.ru/index. php?id=236\&uid $=10067$.

8. Национальный проект «Образование» // Будущее России. Национальные проекты: [сайт].- Текст: электронный. - URL: https://futurerussia.gov.ru/obrazovanie.

9. Human Development Indicators. Russian Federation // United Nations Development Programme: [сайт].- Текст: электронный._URL: http://hdr.undp.org/en/indicators/103706\#.

10. World Population Prospects 2019 // United Nations: [сайт].- Текст: электронный. - URL: https://population. un.org/wpp/.

11. World Population Prospects 2019: Maps // United Nations: [сайт].- Текст: электронный.- URL: https:// population.un.org/wpp/Maps/.

12. World Population Prospects 2019. Demographic Profiles. Russian Federation // United Nations: [сайт].- Текст: электронный._URL:https://population.un.org/wpp/Graphs/1_Demographic\%20Profiles/Russian\%20Federation. pdf.

13. World Population Prospects 2019. Demographic Profiles. Russian Federation // United Nations: [сайт].- Текст: электронный. - URL: https://population.un.org/wpp/Graphs/DemographicProfiles/Line/643.

14. Национальный проект «Демография» // Будущее России. Национальные проекты: [сайт].- Текст: электронный. - URL: https://futurerussia.gov.ru/demografiya.

15. Chernysheva N.A., Perskaya V.V., PetrovA. M., Bakulina A.A. GREEN ENERGY FOR BELT AND ROAD INITIATIVE: ECONOMIC ASPECTS TODAY AND IN THE FUTURE / International Journal of Energy Economics and Policy. 2019. T. 9. № 5. C. 178-185.

16. Kevorkova Z.A., Petrov A. M., Savina N. V. TOWARDS LIABILITIES OF CORPORATE SYSTEMS / International Journal of Civil Engineering and Technology. 2019. T. 10. № 2. C. 1582-1593.

17. Petrov A.M., NikiforovaE.V., Kiseleva N.P., Grishkina S.N., LihtarovaO.V. CREATION OF THE REPORTING ON SUSTAINABLE DEVELOPMENT OF COMPANIES BASED ON SOCIOECONOMIC MEASUREMENT STATISTICS / International Journal of Recent Technology and Engineering. 2019. T. 8. № 2. C. 4005-4012.

18. Sotnikova L.V., PolenovaS.N., Mislavskaya N.A., PetrovA.M., BasovaM.M. SUSTAINABLE DeVElOPMENT, MACRO AND MICRO LEVEL: RUSSIAN AND FOREIGN MODEL / International Journal of Recent Technology and Engineering. 2019. T. 8. № 2. C. 4524-4532.

19. Kosolapova M.V., Muravitskaya N.K., Tolmachev M. N., Melnikova L.A., PetrovA.M. TECHNOLOGY FOR SOLVING THE PROBLEMS RELATED TO THE IMPLEMENTATION OF THE CONCEPT OF PRESERVING CAPITAL IN ACCOUNTING AND STATISTICS / International Journal of Recent Technology and Engineering. 2019. T. 8. № 3. C. 789-792.

20. Kosolapova M.V., PetrovA.M., YshanovI.G., MuravitskayaN.K., NurmuhamedovaH.S. THE ECONOMIC SIGNIFICANCE OF STATISTICAL RESEARCH ACTIVITIES OF REPRESENTATIVE OFFICES OF COMPANIES ABROAD / International Journal of Innovative Technology and Exploring Engineering. 2019. T. 8. № 10. C. 27132722.

21. Petrov A.M., Yurasova I. O., Putihin Y.E., Poluleh M. V., Erohina V.N. ACCOUNTANT MODELING TECHNOLOGY AND STATISTICS IN THE CONTEXT OF THE NEW EDUCATIONAL CONCEPT / International Journal of Innovative Technology and Exploring Engineering. 2019. T. 8. № 12. C. 3214-3217. 
22. Petrov A.M., Kiseleva N.P., KevorkovaZ.A., Melnikova L.A., YshanovI.G. PRESENT DEVELOPMENT PRACTICES FOR TAX, FINANCIAL AND STATISTICAL REPORTING IN THE RUSSIAN FEDERATION / International Journal of Innovative Technology and Exploring Engineering. 2019. T. 8. № 12. C. 3538-3542.

23. Karpova T.P., Petrov A.M., Antonova O. V. DIRECTIONS OF ACCOUNTING DEVELOPMENT IN THE CONDITIONS OF DIGITALIZATION / Journal of Advanced Research in Dynamical and Control Systems. 2018. T. 10. № 7 Special Issue. C. 117-125.

24. Lymar M.P., Kevorkova Z. A., Petrov A. M. THE CONVERGENCE OF NATIONAL AND INTERNATIONAL ACCOUNTING STANDARDS: CHINESE EXPERIENCE / International Journal of Civil Engineering and Technology. 2018. T. 9. № 13. С. $82-94$.

25. Бабаев Ю.А., Друцкая М. В., Кеворкова Ж. А., Листопад Е. Е., Петров А. М. БУХГАЛТЕРСКИЙ УЧЕТ, АНАЛИЗ И АУДИТ ВНЕШНЕЭКОНОМИЧЕСКОЙ ДЕЯТЕЛЬНОСТИ / Учебник для студентов обучающихся по специальности 080109 «Бухгалтерский учет, анализ и аудит» / под редакцией Ю.А. Бабаева. Москва, 2010.

26. Петров А.М., ПолоусЕ.А. ПОВЫШЕНИЕ ТРАНСПАРЕНТНОСТИ ПОКАЗАТЕЛЯ ДЕБИТОРСКОЙ ЗАДОЛЖЕННОСТИ В ОТЧЕТНОСТИ / Международный бухгалтерский учет. 2011. № 6 (156). С. 2-12.

27. Карпова Т.П., Петров А. М., Горбаткова Г. А., Самарина Л. Б., Дашкина Г. Г., Сидорова М. И., Сабанин Р. Л., Ситникова В.А., Листопад Е.Е. БУХГАЛТЕРСКИЙ УЧЕТ В СФЕРЕ УСЛУГ / учебник дЛя студентов высшего профессионального образования, обучающихся по специальности 080109 «Бухгалтерский учет, анализ и аудит» / Под редакцией М.А. Вахрушиной; Москва, 2011. Сер. Читай

28. Петров А.М., МельниковаЛ.А. ФОРМИРОВАНИЕ ОТЧЕТНОСТИ В СООТВЕТСТВИИ С ТРЕБОВАНИЯМИ МСФО КАК ОБЪЕКТИВНАЯ НЕОБХОДИМОСТЬ НА СОВРЕМЕННОМ ЭТАПЕ РАЗВИТИЯ ЭКОНОМИКИ РФ / Проблемы современной экономики. 2017. № 2 (62). С. 105-107.

29. ТЕОРИЯ БУХГАЛТЕРСКОГО УЧЕТА / учебник / Ю.А.Бабаев, А. М.Петров; под ред. Ю.А.Бабаева. Москва, Проспект, 2011. (Изд. 5-е, перераб. и доп.)

30. Петров А.М. ОБЩЕСТВЕННОЕ ПИТАНИЕ 6 в 1: учетная политика, документооборот, калькулирование себестоимости, бухгалтерский учет, налоги, отчетность / А. М. Петров. Москва, 2011. Сер. Полное руководство бухгалтера 